\title{
Podcast: 10 questions with Dr. Peter Piot
}

$\mathrm{D}$ r. Peter Piot has forged a career fighting two of the most feared viruses in recent history. In 1976, he co-discovered Ebola in what is now known as the Democratic Republic of the Congo. And as founding director of UNAIDS, Piot has been a champion in the global response to HIV. For these efforts, he recently received the Canada Gairdner Global Health Award.

Now the Director of the London School of Hygiene \& Tropical Medicine, Piot joined CMAJ in a podcast interview to reflect on his legacy. Lauren Vogel, CMAJ

Tune in at Soundcloud.

CMAJ 2015. DOI:10.1503/cmaj.109-5101

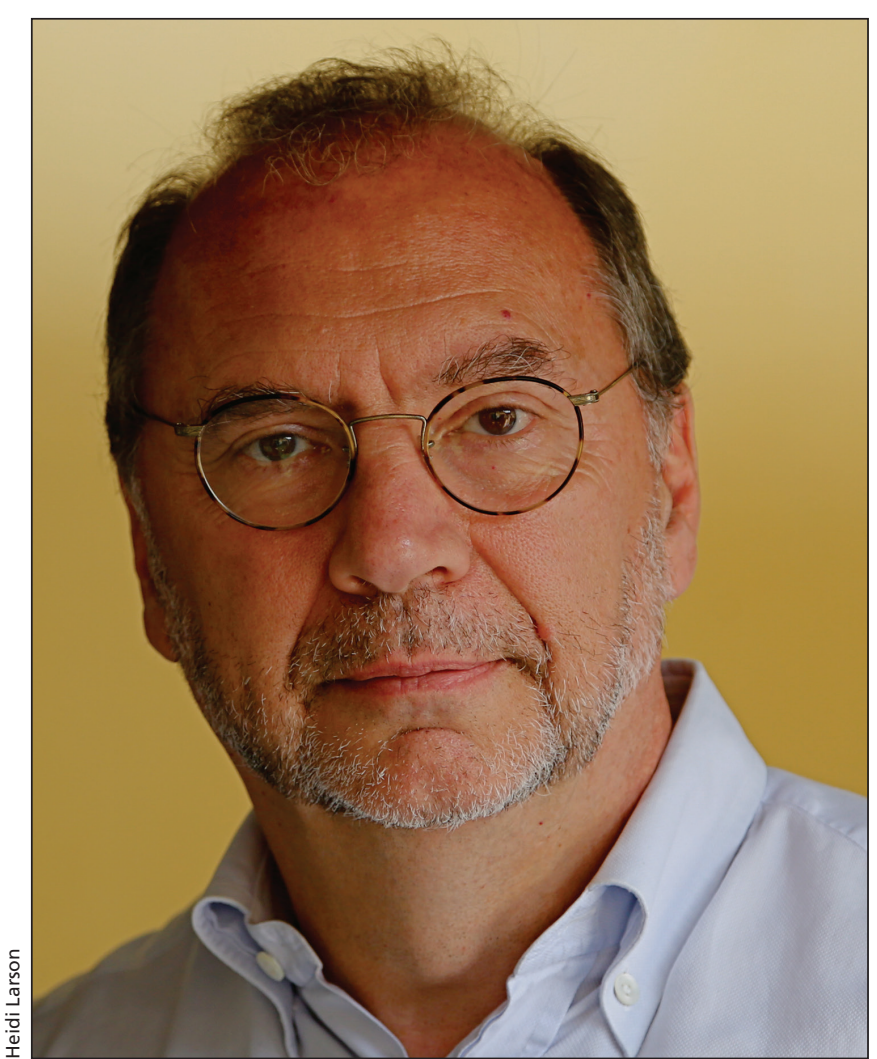

Global health champion Dr. Peter Piot shares insights into Ebola, AIDS and the importance of physician advocacy. 